\section{P112 HOW INTEGRATED ARE WE? A BASHH BCCG SURVEY OF GUM AND SEXUAL HEALTH CLINICS IN THE UK}

'Zana Ladipo*, 'Laura Mitchell, ${ }^{2}$ Sasikala Rajamanoharan, ${ }^{1}$ Mayur Chauhan, ${ }^{3}$ Philip Kell. ${ }^{1}$ New Croft Centre, Newcastle, UK; ${ }^{2}$ Watford General Hospital, Watford, UK; ${ }^{3}$ Torbay Hospital, South Devon, UK

\subsection{6/sextrans-2015-052126.155}

Introduction In 1995, the British Medical Journal published an editorial, "Rethinking sexual health clinics," which recommended integration of genitourinary medicine (GUM) and contraceptive services. In 2010, The White Paper; Healthy lives; Healthy people outlined the aim for England to work towards an integrated model of sexual health service delivery.

Objectives As current levels of service integration within the UK are unknown, this study was undertaken to assess the perceived degree of integration in sexual health services nationally.

Methods A questionnaire was distributed via the British Clinical Cooperative Group to sexual health service leads in the UK between January and June 2012. The questionnaire contained fifteen questions covering issues related to integrated sexual health service provision.

Results A total of 74 questionnaires were returned, which was a response rate of $80 \%$. $62 \%$ saw themselves as integrated sexual health services and a further $19 \%$ had plans to integrate over the subsequent 12 months. However the location of services, service provision, structure and funding of services as well as access and staff training varied considerably between these services. For example, $78 \%$ were located within a single premise while only $52 \%$ provided combined contraception and GUM at each of their clinic sessions.

Conclusion This survey clearly shows that there is commitment towards integration but there are no defining universal standards for integrated services. We therefore recommend development of national standards defining integrated service provision and staff training.

\section{P113 INTIMATE PARTNER VIOLENCE: USE OF EDUCATION AND CLINICAL PRO-FORMA TO INCREASE SCREENING}

Zana Ladipo*, Daisy Ogbonmwan, Jane Hussey, Stephen Bushby. Department of GenitoUrinary Medicine, City Hospitals Sunderland, Sunderland, UK

\subsection{6/sextrans-2015-052126.156}

Background/introduction Intimate partner violence (IPV) can be defined as controlling, coercive or threatening behaviour, violence or abuse between family members or intimate partners regardless of gender or sexuality. BASHH guidelines recommend that clinicians should enquire about IPV and provide support and referral to appropriate services.

Aim(s)/objectives To raise standards in screening for IPV within sexual health service and ensure appropriate support given to those affected.

Methods A retrospective audit of 200 patient records using local standards of $100 \%$ patients must be asked about IPV and of those who declared incidents must have documentation of action taken. Education was then delivered to staff and IPV added to our electronic clinical pro-forma. A re-audit was carried out alongside a survey of staff on the time taken, ease and screening phrases used.

Results In the initial then re-audit screening for IPV was undertaken in $98 \%$ then $100 \%$ of women; $61 \%$ then $99 \%$ of men;
$1.9 \%$ then $2.5 \%$ disclosure; $100 \%$ then $40 \%$ documented offer of support, respectively. Following education $100 \%$ of staff felt comfortable assessing for IPV. Phrases used were variable and adapted to the patient and $80 \%$ of staff felt questioning was timely.

Discussion/conclusion IPV screening improved through the use of education and additional prompting on clinical pro-formas, particularly in male attendees. Screening for IPV was acceptable to staff and did not add significantly to consultation time. Enquiring whether any children were present in the household during IPV was not documented in any disclosed cases and ensuring patients are offered additional support needs further attention within our service.

\section{P114 IMPLEMENTATION OF THE RCOG GUIDELINE ON EMERGENCY CONTRACEPTION ADVICE IN TWO CENTRES WITHIN LONDON}

Catherine Allen*. Barts and the London School of Medicine and Dentistry, London, UK

\subsection{6/sextrans-2015-052126.157}

Background/introduction Since 2011 guidelines by the Royal College of Obstetrics and Gynaecology (RCOG) have stated that those who provide emergency contraception are required to give certain guidance. This includes counselling on the contraception provided as well as protection against unwanted pregnancy in the future in the form of LARC (long-acting reversible contraception). This, however, is neither ubiquitously achieved or documented across the centres offering this service.

Aim(s)/objectives To ascertain the level of concordance with the RCOG guidelines at two centres within London, and highlight the importance of following and documenting them.

Methods A comprehensive search was performed using the emisweb tool in The Essex Lodge surgery in Plaistow on 11/12/14 and in the Highland Road Practice in Bromley on $15 / 01 / 15$.

Results This audit collected data on 57 patients from both the practices, 20 of whom (27\%) had been given no documented advice on either LARC or the medication itself, $12(16 \%)$ contraception advice only, 25 (33\%) LARC only, and only 18 (24\%) advice on both.

\begin{tabular}{lc} 
Abstract P114 Table 1 A table outlining emergency \\
contraception advice given at two GP surgeries in London \\
\hline Advice & Number of patients \\
\hline None recorded & 20 \\
Emergency contraception advice & 12 \\
LARC advice & 25 \\
Both & 18 \\
\hline
\end{tabular}

Discussion/conclusion The varying results between practices indicate that greater care needs to be taken to provide patients with information concerning both the treatment that they are requesting and preventative measures. It is also important to document that these objectives have been achieved with each consultation- something which we have found was not done ubiquitously as is recommended. We have produced an informative poster and hope that this will facilitate changes in the future. 